\title{
Óleos essenciais no controle pós-colheita de Colletotrichum gloeosporioides em mamão
}

\author{
CARNELOSSI, P.R.*; SCHWAN-ESTRADA, K.R.F.**; CRUZ, M.E.S.; ITAKO, A.T.; MESQUINI, R.M. \\ Universidade Estadual de Maringá (UEM), Departamento de Agronomia, Av. Colombo, 5790, CEP: 87020-900, \\ Maringá-Brasil. *Bolsista PIBIC/CNPq. **Bolsista ProdutividadeCNPq krfsestrada@uem.br; schwan@wnet.com.br
}

\begin{abstract}
RESUMO: Os subprodutos de plantas medicinais têm sido estudados como uma alternativa para o controle de doenças de plantas visando amenizar e/ou reduzir o uso abusivo de agrotóxicos, principalmente em condições pós-colheita. Assim, este trabalho teve como objetivo avaliar, in vitro e in vivo, o controle de Colletotrichum gloeosporioides, agente causal da antracnose do mamão em pós-colheita, por óleos essenciais (OEs) de Cymbopogon citratus, Eucalyptus citriodora, Mentha arvensis e Artemisia dracunculus. Para inibição do crescimento micelial in vitro, os OEs foram incorporados ao BDA (Batata-dextrose-ágar) tendo-se observado a inibição total ou parcial do crescimento micelial e da esporulação deste fitopatógeno, dependendo do óleo essencial utilizado. No ensaio in vivo utilizaram-se os OEs de $C$. citratus $(1 \%)$ e E. citriodora (1\%). A inoculação com o fitopatógeno foi concomitante e $24 \mathrm{~h}$ após os tratamentos alternativos, que foram: óleos essenciais de C. citratus e de E. citriodora (1\%) e biomassa cítrica ( $150 \mathrm{~mL} 100$ $\left.\mathrm{L}^{-1}\right)$ (Ecolife®). Os parâmetros avaliados foram severidade da doença, redução da massa, diâmetro, comprimento final dos frutos, $\mathrm{pH}$ e a concentração de sólidos solúveis totais (Bix). Pode-se observar que, no controle da doença, os frutos tratados e imediatamente inoculados com o fitopatógenos apresentaram maior AACPD (Área Abaixo da Curva do Progresso da Doença). Porém, frutos tratados e inoculados $24 \mathrm{~h}$ após os tratamentos apresentaram maior controle da doença, confirmando o potencial dos óleos essenciais testados no presente trabalho.
\end{abstract}

Palavras-chave: óleos essenciais, antracnose, mamão, controle alternativo, plantas medicinais

\begin{abstract}
Essential oils on postharvest control of Colletotrichum gloeosporioides in papaya fruit. The products from medicinal plants have been studied as an alternative in the control of plant diseases in order to mitigate and / or reduce pesticide abuse mainly in postharvest. Thus, the present study aimed to evaluate, in vitro and in vivo, the control of Colletotrichum gloeosporioides, the causative agent of papaya anthracnose, in postharvest using essential oils (EOs) of Cymbopogon citratus, Eucalyptus citriodora, Mentha arvensis and Artemisia dracunculus. For mycelial growth inhibition in vitro, the EOs were incorporated into PDA (potato dextrose agar) and there was total or partial inhibition of mycelial growth and sporulation of plant pathogen, depending on the essential oil used. For the in vitro test, EOs of $C$. citratus $(1 \%)$ and $E$. citriodora (1\%) were employed. The plant pathogen inoculation was concomitant at 24 hours after the alternative treatments, which were: essential oils of $C$. citratus and $E$. citriodora $(1 \%)$ and citrus

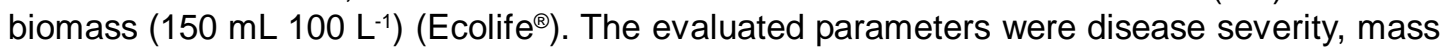
reduction, diameter, fruit final length, $\mathrm{pH}$ and total soluble solid concentration ('Brix). In the disease control, treated fruits immediately inoculated with the plant pathogen showed higher AUDPC (area under disease progress curve). However, treated fruits inoculated 24h after the treatments had greater control of the disease, confirming the potential of the essential oils tested in the present work.
\end{abstract}

Key words: essential oils, anthracnose, papaya, alternative control, medicinal plants

Recebido para publicação em 22/09/2008

Aceito para publicação em 29/04/2009

Rev. Bras. PI. Med., Botucatu, v.11, n.4, p.399-406, 2009. 


\section{INTRODUÇÃO}

A fruticultura moderna está baseada em dois pontos fundamentais, isto é, produzir com quantidade e qualidade e preços competitivos. A exigência do consumidor, não só pela qualidade dos produtos, mas também pela garantia de ausência dos resíduos de agrotóxicos, coloca o produtor de frutíferas em um mercado altamente competitivo (Alvarenga \& Souza, 1997). De acordo com Zambolim et al. (1997), o manejo das doenças em qualquer cultura deve ser empregado para reduzir os danos provocados a níveis economicamente aceitáveis, sem prejuízos para os agroecossistemas, mantendo o seu equilíbrio.

As doenças pós-colheita em frutos são responsáveis por perdas, em muitos casos, superiores a 50\%, antes de chegar à mesa do consumidor, e os que chegam, nem sempre possuem a qualidade desejada (Tavares, 2004). Em geral, os agentes causadores de podridões em pós-colheita apresentam características comuns, que são a capacidade de se estabelecerem no fruto imaturo e permanecerem em estado latente, sem o aparecimento de sintomas, até que haja condições para que o processo de infecção tenha lugar (NerySilva et al., 2001). A antracnose, causada pelo fungo Colletotrichum gloeosporioides, também apresenta essa característica, e os sintomas normalmente aparecem com o amadurecimento do fruto (Alvarez \& Nishijima, 1987; Ventura, 1999).

A antracnose ocorre em todas as regiões produtoras de mamão do mundo e por causar importantes perdas em pós-colheita, é um dos fatores limitantes à exportação de mamão (Liberato \& Tatagiba, 2001). Nos meses mais quentes do ano, na ausência de medidas de controle, sua incidência pode atingir 70 a $100 \%$ dos frutos. Mesmo em frutos destinados à exportação, que recebem tratamento pós-colheita, a antracnose ainda é o principal problema (Liberato \& Costa, 1997).

De acordo com Ventura et al. (2003), para o controle de doenças em pós-colheita de mamão o principal tratamento indicado é o hidrotérmico (48$49^{\circ} \mathrm{C} / 20$ minutos, em seguida $100^{\circ} \mathrm{C} / 20$ minutos). Porém, juntamente com o uso desse tratamento, recomenda-se a aplicação de ceras e fungicidas para garantir uma maior sobrevida ao fruto. A diminuição da eficiência dos produtos utilizados comercialmente no controle da antracnose é fator a ser considerado, uma vez que esse fato é associado ao aparecimento de microorganismos com níveis elevados de tolerância a esses produtos (Alvarez \& Nishijima et al., 1987; Nery-Silva et al., 2001).

O uso intensivo de produtos químicos para controlar doenças em plantas e frutos vem causando prejuízos ao meio ambiente e selecionando espécies de fungos com resistência a fungicidas. Isto justifica, portanto, a busca por métodos alternativos de controle, no qual se incluem o controle biológico e a indução de resistência em plantas pelo o uso de extratos vegetais e óleos essenciais, entre outros (Stangarlin et al., 1999; Schwan-Estrada \& Stangarlin, 2005).

Vários estudos têm comprovado o efeito de extratos e óleos essenciais de plantas medicinais na capacidade de controlar doenças em plantas, tanto por sua atividade antimicrobiana direta quanto indireta (Chao \& Young, 2000; Fiori et al., 2000; Bastos \& Albuquerque, 2004). Como exemplo, Ribeiro \& Bedendo (1999) avaliaram extratos de alho, hortelã, mamona e pimenta no crescimento micelial e esporulação de C. gloeosporioides. Palhano et al. (2004) avaliaram o efeito do óleo essencial de capimlimão (Cymbopogon citratus) e citral isolados ou aplicados junto com pressão hidrostática, na viabilidade de conídios de Colletotrichum gloeosporioides. Chalfoun et al. (2004) avaliaram os óleos essenciais de alho, canela, cravo e tomilho sobre o desenvolvimento micelial dos fungos Rhizopus sp., Penicillium spp., Eurotium repens e Aspergillus niger.

Assim, este trabalho teve como objetivo avaliar, in vitro e in vivo, o controle de Colletotrichum gloeosporioides, agente causal da antracnose do mamão em pós-colheita, por óleos essenciais de Cymbopogon citratus (capim-limão), Eucalyptus citriodora (eucalipto), Mentha arvensis (menta) e Artemisia dracunculus (estragão).

\section{MATERIAL E MÉTODO}

O trabalho foi conduzido no Departamento de Agronomia da Universidade Estadual de Maringá (UEM), Maringá, PR. O experimento in vitro foi realizado no Laboratório de Fitopatologia, e o experimento in vivo, juntamente com a extração dos óleos essenciais, foi realizado no Laboratório de Plantas Medicinais.

Efeito in vitro dos óleos essenciais sobre o crescimento e esporulação de $C$. gloeosporioides O fungo C. gloeosporioides foi isolado diretamente de frutos de mamão "papaya" com sintomas da doença e sinais do patógeno, sendo cultivado em meio BDA (batata-dextrose-ágar) por 15 dias a $25^{\circ} \mathrm{C}$ e sob luz fluorescente.

Para obtenção dos óleos essenciais, folhas de Cymbopogon citratus DC. Stapf (Família Poaceae) (capim limão), Eucalyptus citriodora Hook (Família Myrtaceae) (eucalipto), Mentha arvensis L. (Família Labiatae) (menta) e Artemisia dracunculus L. (Família Asteraceae) (estragão) foram coletadas no Horto de Plantas Medicinais da Universidade Estadual de Maringá e secas em temperatura ambiente por 1 dia. A extração foi pelo método de arraste a vapor (Worwood, 1995). Após a extração, os OEs foram 
esterilizados por filtração em membrana Millipore de $47 \mathrm{~mm}$ de diâmetro.

Para verificar o efeito dos óleos essenciais sobre o crescimento micelial e esporulação do fitopatógeno, alíquotas de 1, 5, 10, 15, 25, $50 \mu \mathrm{L}$ dos óleos essenciais das plantas citadas anteriormente, foram colocadas no centro de placas de Petri contendo BDA e distribuídas sobre a superfície do meio com auxilio da alça de Drigalsky. Após 2 h, um disco de 8 $\mathrm{mm}$ de diâmetro contendo micélio de C. gloeosporioides com cerca de 15 dias de idade em BDA, foi repicado para o centro das placas que foram vedadas com filme plástico e mantidas a $25^{\circ} \mathrm{C}$ no escuro. No tratamento testemunha não se adicionou nenhum tipo de produto ao meio de cultura. As avaliações foram realizadas por medições diárias do diâmetro das colônias (média de duas medidas diametralmente opostas), 24 horas após a instalação do experimento e perdurou até o momento em que as colônias fúngicas cobriram $2 / 3$ da superfície do meio de cultura. Para o cálculo da porcentagem de inibição do crescimento micelial (PIC), (Bastos, 1997), foi aplicada a fórmula:

$\mathrm{PIC}=\underline{\text { Cresc. } \text { testemunha }- \text { Cresc. } \text { tratamento }} \times 100$

Cresc. testemunha

Ao final deste período avaliou-se a esporulação do fungo. A suspensão de conídios foi preparada colocando-se $1 \mathrm{~mL}$ água destilada esterilizada nas placas com a cultura do fungo raspando-a suavemente com alça de Drigalsky. A suspensão foi filtrada em gaze e a quantidade de conídios foi determinada pela contagem em câmara de Neubauer. O número de conídios produzidos foi expresso em números de conídios por $\mathrm{cm}^{2}$. O delineamento experimental foi ao acaso, no esquema fatorial $(3 \times 6)+1$ ( 3 óleos essenciais, 6 concentrações, testemunha e 4 repetições).

\section{Efeito in vivo dos óleos essenciais no controle da antracnose em frutos de mamão papaya}

Os frutos de mamão papaya foram adquiridos no CEASA da cidade de Maringá, Paraná, e todos apresentavam a coloração verde. Os frutos foram identificados, pesados e determinados os diâmetros e comprimentos. Logo após, foram submetidos previamente a uma desinfestação superficial com hipoclorito de sódio $(0,5 \%)$ por $1 \mathrm{~min}$, lavados com água destilada, e imersos por 1 min nas soluções contendo cada tratamento. Em seguida, os frutos foram colocados em bandejas e secos em temperatura ambiente. A inoculação com o fitopatógeno foi realizada pela deposição de disco de micélio (4 mm de diâmetro) de C. gloeosporioides em três pontos opostos na região equatorial do fruto.

Os tratamentos utilizados foram óleos essenciais de C. citratus e de E. citriodora (1\%) e biomassa cítrica $\left(\right.$ Ecolife $\left.^{\circledast}\right)\left(1 \mathrm{~L} \mathrm{ha}^{-1}\right)$. A inoculação foi concomitante e $24 \mathrm{~h}$ após os tratamentos. Como testemunha utilizou-se fruto com e sem inoculação do fitopatógeno.

Foram utilizados três frutos/tratamento, com quatro repetições, totalizando 12 frutos por tratamento. Após as inoculações, as bandejas contendo os frutos foram colocadas em câmara úmida por $24 \mathrm{~h}$ e em temperatura ambiente. Após a retirada da câmara úmida as bandejas permaneceram em temperatura ambiente por 8 dias sendo realizadas avaliações da severidade a cada dois dias totalizando quatro avaliações. Para isso foi quantificado o diâmetro das lesões $(\mathrm{mm})$ e posteriormente calculada a área abaixo da curva de progresso da doença (AACPD), conforme a equação apresentada por Campbell \& Madden (1990). Avaliou-se também a massa, diâmetro e comprimento final dos frutos de mamão bem como pH e a concentração de sólidos solúveis totais ('Brix) determinado no suco dos frutos, utilizando-se refratômetro manual, tipo Atago, com escala de 0 a 32-Brix (Carvalho et al., 1990).

Posteriormente, aplicou-se a análise de variância (ANOVA) e, havendo significância a $5 \%$ de probabilidade pelo teste $F$, compararam-se às médias dos tratamentos por meio do teste de Tukey, a $5 \%$ de probabilidade. Essas análises estatísticas foram realizadas por meio do programa SISVAR v.4.2 (Ferreira, 2003).

\section{RESULTADO E DISCUSSÃO}

\section{Efeito in vitro dos óleos essenciais sobre o crescimento micelial e esporulação de $C$. gloeosporioides}

Os resultados apresentados na Tabela 1 mostram que houve diferença significativa, entre os tratamentos na inibição do crescimento micelial de C. gloeosporioides. Todos os óleos testados inibiram em $100 \%$ o crescimento micelial do fungo na alíquota de $50 \mu \mathrm{L}$. O óleo de $C$. citratus foi o mais eficiente, pois causou inibição de $100 \%$ a partir da alíquota de $10 \mu \mathrm{L}$.

Na presença do óleo de $A$. dracunculus, os maiores valores na inibição do crescimento foram observados nas maiores concentrações, sendo superiores à testemunha. Para os óleos de $M$. arvensis e E. citriodora, a inibição foi dose dependente, isto é, a medida que se aumenta à alíquota, aumenta a porcentagem de inibição; porém, as alíquotas de 1, 5 e $10 \mu \mathrm{L}$, para ambos, não foram eficientes, tendo um desempenho estatisticamente semelhante ao da testemunha. Resultados semelhantes foram obtidos por Fiori et al. (2000) trabalhando com os óleos essenciais de E. citriodora, 
TABELA 1. Inibição do crescimento micelial (\%), in vitro, de Colletotrichum gloeosporioides na presença de diferentes alíquotas de óleos essenciais de Cymbopogon citratus (capim-limão); Eucalyptus citriodora (eucalipto); Mentha arvensis (menta) e Artemisia dracunculus (estragão).

\begin{tabular}{ccccc}
\hline & \multicolumn{4}{c}{ Inibição crescimento micelial (\%) } \\
\cline { 2 - 5 } Alíquotas $(\mu \mathrm{L})$ & C. citratus & E. citriodora & M. arvensis & A. dracunculus \\
\hline 1 & $1,0 \mathrm{ab}$ & $3,0 \mathrm{a}$ & $0 \mathrm{ab}$ & $9,4 \mathrm{a}$ \\
5 & $50,2 \mathrm{a}$ & $19,0 \mathrm{a}$ & $6,7 \mathrm{a}$ & $0 \mathrm{ab}$ \\
10 & $100 \mathrm{C}$ & $21,7 \mathrm{a}$ & $20,2 \mathrm{a}$ & $0 \mathrm{~b}$ \\
15 & $100 \mathrm{c}$ & $36,1 \mathrm{~b}$ & $21,6 \mathrm{~b}$ & $38,0 \mathrm{~b}$ \\
25 & $100 \mathrm{c}$ & $100 \mathrm{~b}$ & $63,0 \mathrm{c}$ & $57,4 \mathrm{c}$ \\
50 & $100 \mathrm{C}$ & $100 \mathrm{~b}$ & $100 \mathrm{C}$ & $100 \mathrm{~d}$ \\
Testemunha & $7,5 \mathrm{ab}$ & $7,7 \mathrm{a}$ & $7,4 \mathrm{a}$ & $7,4 \mathrm{ab}$ \\
\hline CV $(\%)$ & 26,7 & 25,0 & 19,2 & 19,7 \\
\hline
\end{tabular}

Médias seguidas pela mesma letra na coluna não diferem estatisticamente pelo teste de Tukey ao nível de $5 \%$ de probabilidade.

C. citratus e Ageratum conyzoides, onde verificaram que a inibição do crescimento micelial de Didymella bryoniae em $100 \%$ nas alíquotas testadas $(20,40$, $60,100,200,500$ e $1000 \mu \mathrm{L}$ ), e que o óleo essencial de Achillea millefolium nas alíquotas de 20, 40, 60, 100 e $200 \mu \mathrm{L}$ promoveu inibição do crescimento micelial em 35,02, 50,46, 57,02, 74,53 e 89,29\%, respectivamente, e nas alíquotas de 500 e $1000 \mu \mathrm{L}$ ocorreu $100 \%$ de inibição. Singh et al. (1992) verificaram a ação do óleo de $M$. arvensis sobre 23 espécies de fungos, entre eles Alternariasp, Fusarium moliniformee $F$. solanie observaram inibição de $100 \%$ do crescimento micelial, a partir de $2.000 \mathrm{mg} \mathrm{mL}^{-1}$, afirmando que este óleo poderia ser usado no controle de doenças de plantas. Alves et al. (2003) relataram a eficiência dos óleos de Cymbopogon citratus, $C$. nardus e E. citriodora no controle in vitro dos fungos Colletotrichum gloeosporioides, C. musaee Fusarium subglutinans f. sp. ananas. Pereira et al. (2006), utilizando óleo essencial de menta, observaram inibição do desenvolvimento micelial de Aspergillus nigere A. flavus nas concentrações 1500 e $2000 \mathrm{mg}$ $\mathrm{mL}^{-1}$, respectivamente.

Em relação à esporulação de $C$. gloeosporioides, o óleo essencial de $C$. citratus foi o mais eficiente, inibindo $100 \%$ a esporulação a partir da alíquota de $10 \mu \mathrm{L}$. Para os óleos de E. citriodorae M. arvensis, a partir da alíquota de 15 e $10 \mu \mathrm{L}$, respectivamente, começou a se observar uma redução na esporulação, sendo que as demais alíquotas não diferiram da testemunha (Tabela 2).

Para o óleo essencial de $A$. dracunculus, a inibição total da esporulação foi observada na alíquota de $50 \mu \mathrm{L}$. $\mathrm{Na}$ alíquota de $25 \mu \mathrm{L}$ observou-se esporulação superior à testemunha, entretanto nas demais concentrações utilizadas a esporulação foi inferior e estatisticamente diferente. Os óleos essenciais de plantas medicinais têm apresentado efeito fungicida tanto na esporulação quanto na geminação de conídios de diferentes fitopatógenos. Palhano et al. (2004), que avaliaram o efeito do óleo essencial de $C$. citratus e citral isolados ou aplicados junto com pressão hidrostática na viabilidade de conídios de C. gloeosporioides, verificaram que houve inibição quando submetidos à pressão hidrostática de $350 \mathrm{MPa}$ por 30 min mas, quando tratados com o óleo essencial ou com citral, a pressão hidrostática necessária foi de $150 \mathrm{MPa}$. Resultados in vitro obtidos por Carré et al. (2006) sobre o efeito de Artemisia camphorata e quitosana no crescimento micelial e esporulação de Colletotrichum musae, agente causal da antracnose pós-colheita em banana, demonstraram inibição de $41 \%$ no crescimento micelial de $86 \%$ na esporulação, em meio sólido, embora tenha estimulado o crescimento micelial em meio líquido. Para quitosana no meio sólido, ocorreu inibição do crescimento micelial em até $32 \%$ e estímulo da esporulação, enquanto que em meio líquido ocorreu $48 \%$ de inibição do crescimento. Medice et al. (2007) constataram que os óleos de Corymbia citriodora, $C$. nardus, Azadirachta indicae Thymus vulgaris tiveram $100 \%$ de efeito inibitório sobre a germinação de urediniósporos de Phakopsora pachyrhizi.

\section{Controle pós-colheita de $C$. gloeosporioides em frutos de mamão papaya \\ Os frutos tratados com OE de E. citratus e imediatamente inoculados com C. gloeosporioides apresentaram os maiores valores para sólidos solúveis totais, diferindo estatisticamente dos demais tratamentos (Tabela 3).}


TABELA2. Esporulação ( $\mathrm{n}$ o conídios $\mathrm{cm}^{-2}$ ) de Colletotrichum gloeosporioides na presença de diferentes alíquotas de óleo essencial (OE) de Cymbopogon citratus (capim-limão); Eucalyptus citriodora (eucalipto); Mentha arvensis (menta) e Artemisia dracunculus (estragão).

\begin{tabular}{ccccc}
\hline & \multicolumn{4}{c}{$\mathbf{N}^{\mathbf{0}}$ conídios $\mathbf{~ c m}^{-2}\left(\mathbf{\times 1 0 ^ { 4 } )}\right.$} \\
\cline { 2 - 5 } Alíquotas $(\mu \mathrm{L})$ OE & C. citratus & E. citriodora & M. arvensis & A. dracunculus \\
\hline 1 & $5,9 \mathrm{a}$ & $12,4 \mathrm{ab}$ & $4,9 \mathrm{~b}$ & $2,0 \mathrm{~d}$ \\
5 & $5,7 \mathrm{a}$ & $11,8 \mathrm{ab}$ & $4,8 \mathrm{bc}$ & $1,6 \mathrm{~d}$ \\
10 & $0 \mathrm{C}$ & $13,6 \mathrm{ab}$ & $3,3 \mathrm{~cd}$ & $2,3 \mathrm{~cd}$ \\
15 & $0 \mathrm{c}$ & $9,4 \mathrm{~b}$ & $6,9 \mathrm{a}$ & $3,4 \mathrm{C}$ \\
25 & $0 \mathrm{c}$ & $0 \mathrm{c}$ & $1,9 \mathrm{de}$ & $6,4 \mathrm{a}$ \\
50 & $0 \mathrm{c}$ & $0 \mathrm{c}$ & $0,5 \mathrm{e}$ & $0 \mathrm{e}$ \\
Testemunha & $1,7 \mathrm{~b}$ & $14,0 \mathrm{a}$ & $4,9 \mathrm{~b}$ & $4,9 \mathrm{~b}$ \\
\hline CV $(\%)$ & 24,5 & 21,5 & 16,8 & 17,6 \\
\hline
\end{tabular}

Médias seguidas pela mesma letra não diferem estatisticamente pelo Teste de Tukey ao nível de $5 \%$ de probabilidade.

TABELA3. Teores médios de sólidos solúveis totais ('Brix), pH e reduções de massa fresca (g), diâmetro (mm) e comprimento $(\mathrm{mm})$ dos frutos de mamão papaya, em diferentes tratamentos, com inoculação do patógeno concomitante aos tratamentos e avaliado após 8 dias de armazenamento em condição ambiental.

\begin{tabular}{lcccccc}
\hline & & & \multicolumn{3}{c}{ Redução } \\
\cline { 5 - 7 } \multicolumn{1}{c}{ Tratamentos } & $\begin{array}{c}\text { Sólidos } \\
\text { Solúveis } \\
\text { (-Brix) }\end{array}$ & $\mathbf{p H}$ & $\begin{array}{c}\text { Massa } \\
\text { fresca (g) }\end{array}$ & $\begin{array}{c}\text { Diâmetro } \\
\text { (mm) }\end{array}$ & $\begin{array}{c}\text { Comprimento } \\
\text { (mm) }\end{array}$ \\
\hline OE C.citratus & $10,4 \mathrm{~b}$ & $4,2 \mathrm{~b}$ & $16,5 \mathrm{~b}$ & $1,5 \mathrm{a}$ & $0,7 \mathrm{~b}$ \\
OE E. citriodora & $11,8 \mathrm{a}$ & $4,4 \mathrm{a}$ & $32,8 \mathrm{a}$ & $1,2 \mathrm{~b}$ & $1,1 \mathrm{~b}$ \\
Biomassa cítrica & $12,1 \mathrm{a}$ & $4,4 \mathrm{a}$ & $7,5 \mathrm{c}$ & $0,7 \mathrm{~b}$ & $1,0 \mathrm{~b}$ \\
Testemunha s/ inoculação & $11,9 \mathrm{a}$ & $4,2 \mathrm{~b}$ & $4,3 \mathrm{c}$ & $1,1 \mathrm{~b}$ & $1,4 \mathrm{~b}$ \\
Testemunha c/ inoculação & $11,6 \mathrm{a}$ & $4,4 \mathrm{a}$ & $5,7 \mathrm{c}$ & $1,9 \mathrm{a}$ & $1,3 \mathrm{~b}$ \\
\hline C.V (\%) & 5,4 & 0,5 & 29,2 & 20,3 & 11,0 \\
\hline
\end{tabular}

Médias seguidas pela mesma letra não diferem estatisticamente pelo teste de Tukey ao nível de $5 \%$ de probabilidade.

Os tratamentos com OE de E. citriodora e biomassa cítrica apresentaram os maiores valores de $\mathrm{pH}$, não diferindo da testemunha com inoculação. Com relação à perda de massa, houve diferenças significativas entre os tratamentos sendo que as maiores perdas foram verificadas nos frutos tratados com OE E. citriodora e C. citratus, quando comparados com os demais tratamentos. Já os frutos tratados com biomassa cítrica, mesmo apresentando uma perda de peso menor que a observada nos tratamentos com os óleos essenciais, não diferiram das testemunhas com e sem inoculação. Para a redução do diâmetro dos frutos não houve diferenças significativas nos tratamentos com $C$. citratus e a testemunha com inoculação, sendo que os demais tratamentos foram superiores, sendo que o tratamento com biomassa cítrica apresentou melhor resultado.
Os frutos tratados e inoculados 24 horas após os tratamentos, não apresentaram diferenças significativas entre si, para os valores de sólidos solúveis totais (Tabela 4).

Em relação ao $\mathrm{pH}$, os tratamentos com biomassa cítrica e OE de C.citratus, apresentaram valores mais altos do que os observados no $O E$ de E. citriodora e testemunha sem inoculação. Para o parâmetro comprimento dos frutos não houve diferença significativa entre os tratamentos resultado semelhante ao obtido nos frutos tratados e imediatamente inoculados. Com relação à redução de massa dos frutos houve diferença entre os tratamentos sendo a maior redução observada nos frutos tratados com óleo de E. citriodora seguida pelos tratamentos com óleo de $C$. citratus e biomassa cítrica. No parâmetro redução do diâmetro dos frutos 
o tratamento com OE de $C$. citratus não foi eficiente, sendo estatisticamente semelhante à testemunha inoculada. Já os demais tratamentos foram superiores, evitando perdas no diâmetro dos frutos.

Em relação área abaixo da curva de progresso da doença para os frutos tratados e inoculados imediatamente (Figura 1), a menor AACPD foi observada no tratamento com $C$. citratus, $E$. citriodora, seguido pela biomassa cítrica, demonstrando que a doença foi menos severa nesses tratamentos, ao passo que os mesmos diferiram da testemunha com inoculação.

Já para o progresso da doença dos frutos tratados e inoculados após 24 h (Figura 2), não foram observadas diferenças significativas entre os tratamentos, porém a menor AACPD foi observada no tratamento com $C$. citratus, resultado semelhante ao dos frutos tratados e inoculados imediatamente.

TABELA 4. Teores médios de sólidos solúveis totais (Brix) e reduções de massa fresca (g), diâmetro ( $\mathrm{mm}$ ) e comprimento $(\mathrm{mm})$ dos frutos de mamão papaya, em distintos tratamentos, inoculados com Colletotrichum gloeosporioides, 24 horas após os tratamentos e avaliados após 8 dias de armazenamento em condição ambiental.

\begin{tabular}{lccccc}
\hline \multicolumn{1}{c}{ Tratamentos } & $\begin{array}{c}\text { Sólidos } \\
\text { Solúveis } \\
\text { (-Brix) }\end{array}$ & $\mathbf{p H}$ & $\begin{array}{c}\text { Massa } \\
\text { fresca } \\
(\mathbf{g})\end{array}$ & $\begin{array}{c}\text { Redução } \\
\text { Diâmetro } \\
(\mathbf{m m})\end{array}$ & $\begin{array}{c}\text { Comprimento } \\
(\mathbf{m m})\end{array}$ \\
\hline OE C.citratus & $11,7 \mathrm{a}$ & $4,3 \mathrm{~b}$ & $13,1 \mathrm{~b}$ & $2,4 \mathrm{a}$ & $2,9 \mathrm{a}$ \\
OE E. citriodora & $10,1 \mathrm{a}$ & $4,2 \mathrm{c}$ & $35,1 \mathrm{a}$ & $1,1 \mathrm{~b}$ & $2,1 \mathrm{a}$ \\
Biomassa cítrica & $11,0 \mathrm{a}$ & $4,3 \mathrm{~b}$ & $11,1 \mathrm{~b}$ & $1,3 \mathrm{~b}$ & $3,4 \mathrm{a}$ \\
Testemunha s/ inoculação & $11,9 \mathrm{a}$ & $4,2 \mathrm{c}$ & $4,4 \mathrm{c}$ & $1,1 \mathrm{~b}$ & $2,3 \mathrm{a}$ \\
Testemunha c/ inoculação & $11,9 \mathrm{a}$ & $4,4 \mathrm{a}$ & $5,8 \mathrm{c}$ & $2,6 \mathrm{a}$ & $2,4 \mathrm{a}$ \\
\hline C.V (\%) & 7,8 & 0,4 & 24,3 & 29,2 & 30,9 \\
\hline
\end{tabular}

Médias seguidas pela mesma letra não diferem estatisticamente pelo Teste de Tukey ao nível de $5 \%$ de probabilidade.

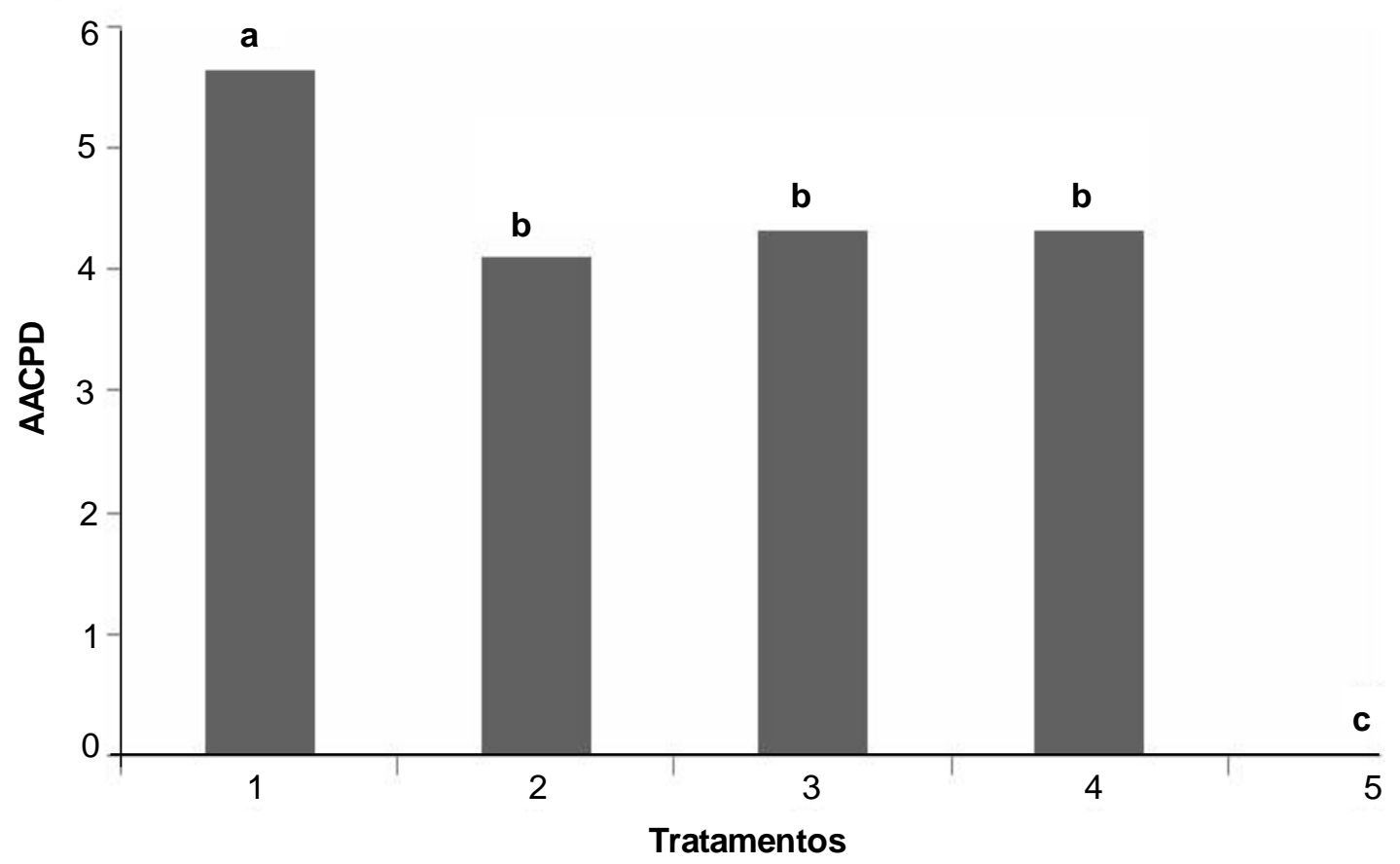

FIGURA 1. Área abaixo da curva de progresso da doença (AACPD), para os valores de diâmetro das lesões (mm), em frutos de mamão tratados e imediatamente inoculados com C. gloeosporioides. Tratamentos: 1- Testemunha com inoculação; 2- Óleo essencial C.citratus; 3- Óleo essencial E. citriodora; 4- Biomassa cítrica; 5- Testemunha sem inoculação. Letras distintas representam diferença significativa entre os tratamentos pelo teste de Tukey ao nível de $1 \%$ de probabilidade. 
Pode-se inferir que no controle da doença, os frutos tratados e imediatamente inoculados com o fitopatógenos apresentaram maior AACPD, demonstrando que a doença ocorre com mais intensidade, porém, frutos tratados e inoculados 24 h após os tratamentos apresentaram maior controle da doença (menor AACPD).

Trabalhos obtendo os mesmos resultados avaliando o potencial de óleos essenciais no controle de pós-colheita de fitopatógenos já foram relatados. Cruz (2003) testou óleos essenciais de Allium sativum, Copaifera langsdorfii, Cinnamomum zeylanicum e Eugenia caryophyllata no controle de antracnose em frutos de banana (C. musae) e verificou que o maior percentual de controle da doença nos frutos foi proporcionado pelos óleos essenciais de $A$. sativum, seguido pelos tratamentos com óleo essencial de $C$. langsdorfii, E. caryophyllata e C. zeylanicum. $O$ tratamento controle proporcionou aos frutos o menor percentual de controle $(5,19 \%)$. Bastos \& Albuquerque (2004) verificaram que óleo essencial de pimenta-demacaco (Piper aduncum) inibiu $100 \%$ do crescimento micelial e da germinação de C. musae para concentrações acima de $100 \mu \mathrm{g} \mathrm{mL}^{-1}$ do óleo, enquanto que, in vivo, concentrações do óleo acima de $1 \%$ foram capazes de impedir a manifestação de podridões nos frutos de banana "Prata". Carré et al. (2006) verificaram que o extrato bruto de cânfora (20\%) e soluções de quitosana $\left(250 \mu \mathrm{g} \mathrm{mL}^{-1}\right)$ foram eficientes no controle de antracnose em frutos de banana quando comparados aos frutos não tratados. O extrato bruto de cânfora e as soluções de quitosana foram eficientes no controle da antracnose, quando comparados aos frutos não tratados, ocorrendo redução da severidade de até $66 \%$ para o extrato de cânfora e $63 \%$ para a solução de quitosana.

Assim, neste trabalho verificou-se que os óleos essenciais testados possuem potenciais no controle de C. gloeosporioides em frutos de mamão, sendo que a sua utilização poderia ser uma opção de controle em cultivos orgânicos ou em cultivos convencionais em sistema de manejo integrado reduzindo, assim, a aplicação de fungicidas comerciais.

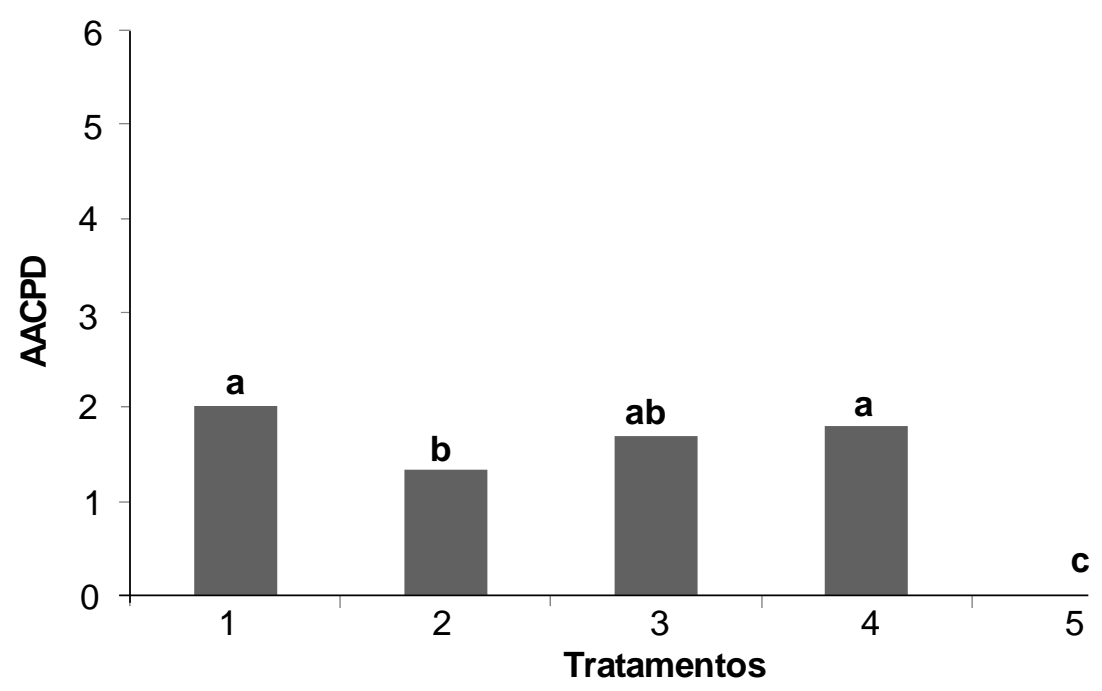

FIGURA 2. Área abaixo da curva de progresso da doença (AACPD), para os valores de diâmetro das lesões (mm), em frutos de mamão tratados e inoculados 24 horas após os tratamentos com C. gloeosporioides. Tratamentos: 1Testemunha com inoculação; 2-Óleo essencial $C$. citratus; 3- Óleo essencial $E$. citriodora; 4-Biomassa cítrica; 5Testemunha sem inoculação. Letras distintas representam diferença significativa entre os tratamentos pelo teste de Tukey ao nível de $1 \%$ de probabilidade.

\section{REFERÊNCIA}

ALVARENGA, A.A.; SOUZA, C.R. Tratos culturais para Pessegueiros/Ameixeiras/ Nectarinas. Informe Agropecuário, v.18, n.189, p.51-5, 1997.

ALVAREZ, A.M.; NISHIJIMA, W.T. Postharvest diseases of papaya. Plant Disease, v.71, n.7, p.681-6, 1987.

ALVES, E.S.S.B. et al. Avaliação de óleos essenciais na inibição do crescimento de fungos de fruteiras tropicais. In: FITOPATOLOGIA BRASILEIRA, 36., 2003, Uberlândia. Resumos ... Lavras: Sociedade Brasileira de Fitopatologia, 2003. p.343.
BASTOS, C.N. Efeito do óleo de Piper aduncum sobre Crinipelis e outros fungos fitopatogênicos. Fitopatologia Brasileira, v.22, n.3, p.441-3, 1997.

BASTOS, C.N.; ALBUQUERQUE, P.S.B. Efeito do óleo essencial de Piper aduncum no controle em póscolheita de Colletotrichum musae em banana. Fitopatologia Brasileira, v.29, n.5, p.555-7, 2004.

CAMPBELL, C.L.; MADDEN, L. Introduction to plant disease epidemiology. New York: John Wiley \& Sons, 1990. 532p.

CARRÉ, V. et al. Controle pós-colheita de Colletotrichum musae em banana (Musa sp) por cânfora (Artemisia 
camphorata) e quitosana. Scientia Agrária Paranaensis, v.5, n.1, p.57-66, 2006.

CARVALHO, C.R.L. et al. Análises químicas de alimentos. Campinas: Instituto de Tecnologia de Alimentos, 1990. 121p. (Manual Técnico).

CHALFOUN, S.M. et al. Effect of powdered spice treatments growth, sporulation and production of aflatoxin by toxigenic fungi. Ciência e Agrotecnologia, v.28, n.4, p.856-62, 2004.

CHAO, S.C.; YOUNG, D.G. Screening for inhibitory activity of essential oils ou selected bacteria, fungi and viruses. Journal Essentials Oil Research, v.12, n.4, p.630-49, 2000.

FERREIRA, D.F. Sisvar versão 4.2. DEX/UFLA, 2003.

FIORI, A.C.G. et al. Antifungal activity of leaf extracts and essential oils of some medicinal plants against Didymella bryoniae. Journal Phytopathology, v.148, n.78, p.483-7, 2000.

LIBERATO, J.R.; COSTA, H. Incidência de antracnose e podridão peduncular em frutos de mamoeiro em Linhares - ES. In: FITOPATOLOGIA BRASILEIRA, 30.,1997, Poços de Calda. Resumos ... Lavras: Sociedade Brasileira de Fitopatologia, 1997. p.276.

LIBERATO, J.R.; TATAGIBA, J.S. Avaliação de fungicidas in vitro e em pós-colheita para o controle da antracnose e da podridão peduncular em frutos de mamão. Summa Phytopathologica, v.26, n.4, p.409-14, 2001.

MEDICE, R. et al. Óleos essenciais no controle da ferrugem asiática da soja Phakopsora pachyrhizi Syd. \& P. Syd. Ciência e Agrotecnologia, v.31, n.1, p.83-90, 2007. NERY-SILVA, F.A. et al. Controle químico da podridão peduncular de mamão causada por Colletotrichum gloeosporioides. Ciência e Agrotecnologia, v.25, n.3, p.519-24, 2001.

PALHANO, L.F. et al. Inactivation of Colletotrichum gloeosporioides spores by high hydrostatic pressure combined with citral or lemongrass essential oil. International Journal of Food Microbiology, v.95, n.1, p.61-6, 2004.
PEREIRA, M.C. et al. Inibição do desenvolvimento fúngico através da utilização de óleos essenciais de condimentos. Ciência e Agrotecnologia, v.30, n.4, p.7318, 2006.

RIBEIRO, L.F.; BEDENDO, I.P. Efeito inibitório de extratos vegetais sobre Colletotrichum gloeosporioides - agente causal da podridão de frutos de mamoeiro. Scientia Agrícola, v. 56, n.4, p.1267-71, 1999.

SCHWAN-ESTRADA, K.R.F.; STANGARLIN, J.R. Extratos e óleos essenciais de plantas medicinais na indução de resistência. In: CAVALCANTI, L.S. et al. Indução de resistência em plantas a patógenos e insetos. Piracicaba: Fealq, 2005. p.125-32.

SINGH, S.P. et al. Antibacterial and antifungal activities of Mentha arvensis essential oil. Fitoterapia, v.63, n.1, p.768, 1992.

STANGARLIN, J.R. et al. Plantas medicinais e controle alternativo de fitopatógenos. Biotecnologia Ciência \& Desenvolvimento, v.2, n.11, p.16-24, 1999.

TAVARES, G.M. Controle químico e hidrotérmico da antracnose em frutos de mamoeiro (Carica papaya L.) na pós-colheita. 2004. 55p. Dissertação (Mestrado em Fitopatologia) - Departamento de Fitopatologia, Universidade Federal de Lavras, Lavras.

VENTURA, J.A. Táticas de controle no manejo integrado de doenças. In: ENCONTRO NACIONAL SOBRE FRUTICULTURA DE CLIMA TEMPERADO, 2., 1999, Fraiburgo. Anais... Fraiburgo: UnC/EPAGRI/PMF, 1999. p.139-43.

VENTURA, J.A.; COSTA, H.; TATAGIBA, J.S. Manejo das doenças do mamoeiro. In: MARTINS, D.S.; COSTA, A.F.S. A cultura do mamoeiro: tecnologias de produção. Vitória, ES: Incaper, 2003. p.231-67.

WORWOOD, S. Aromaterapia: um guia de A a Z para o uso terapêutico dos óleos essenciais. São Paulo: Editora Best Seller, 1995. 251p.

ZAMBOLIM, L.; VALE, F.X.R.; COSTA, H. Controle integrado das doenças de hortaliças. Viçosa: UFV, 1997. $122 p$. 